\title{
Eating Competence among a Select Sample of Brazilian Adults: Translation and Reproducibility Analyses of the Satter Eating Competence Inventory
}

\author{
Fabiana Lopes Nalon de Queiroz ${ }^{1, *}$, Eduardo Yoshio Nakano ${ }^{2}$ (D) , Verônica Cortez Ginani ${ }^{1}$, \\ Raquel Braz Assunção Botelho ${ }^{1}\left(\mathbb{D}\right.$, Wilma Maria Coelho Araújo ${ }^{1}$ and Renata Puppin Zandonadi ${ }^{1, * \mathbb{C}}$ \\ 1 Department of Nutrition, Faculty of Health Sciences, Campus Universitário Darcy Ribeiro, \\ University of Brasília, Distrito Federal 70910-900, Brazil; vcginani@gmail.com (V.C.G.); \\ raquelbabotelho@gmail.com (R.B.A.B.); wilma.araujo@terra.com.br (W.M.C.A.) \\ 2 Department of Statistics, University of Brasilia, Brasilia 70910-900, Brazil; eynakano@gmail.com \\ * Correspondence: fabinalon@hotmail.com (F.L.N.d.Q.); renatapz@yahoo.com (R.P.Z.)
}

Received: 17 June 2020; Accepted: 17 July 2020; Published: 19 July 2020

\begin{abstract}
This study aimed to translate and validate the Satter Eating Competence Inventory $\left(\mathrm{ecSI} 2.0^{\mathrm{TM}}\right)$ from English to Brazilian Portuguese. The process included three steps: (i) translation and back-translation of the original ecSI2.0 $0^{\mathrm{TM}}$ to Brazilian Portuguese; (ii) evaluation of its reproducibility; (iii) a pilot study to validate the Brazilian version of the Satter Eating Competence Inventory (ecSI2. $0^{\mathrm{TM}} \mathrm{BR}$ ) for a selected sample of the Brazilian adult population (internal consistency and factor validity). The reproducibility (test-retest reliability) was verified using the intraclass correlation coefficient (ICC) obtained by the responses of 32 Brazilian adults. All domains of the ecSI2.0 ${ }^{\mathrm{TM}} \mathrm{BR}$ and the total score showed ICC $>0.8$. Considering the entire questionnaire, none of the domains presented significant divergences among the participants' responses $(p<0.001)$. In the pilot study with 662 individuals, $74.9 \%(n=496)$ were female, mean age was $40.33 \pm 12.55$, and they presented a higher level of schooling and income. Analyses revealed Cronbach's alpha coefficients of 0.869 for the ecSI2.0 ${ }^{\mathrm{TM}} \mathrm{BR}$ total scale, 0.793 for Eating Attitudes, 0.527 for Internal Regulation, 0.728 for Food Acceptance, and 0.822 for Contextual Skills. In general, the ecSI2.0 ${ }^{\mathrm{TM} B R}$ presented good acceptability, showing total floor and ceiling effects of $\leq 0.6 \%$. Factor validity was examined by confirmatory factor analysis. The four domains presented a good fit in the confirmatory factor analysis: RMSEA $=0.0123$ (95\% CI: $0-0.0266) ; \mathrm{CFI}=0.998 ; \chi^{2}=75.9 ; \mathrm{df}=69 ; p=0.266$. The ecSI2. $0^{\mathrm{TM}} \mathrm{BR}$ is the first tool designed to measure eating competence (EC) in the Brazilian population, showing good reproducibility and internal consistency. We expect the ecSI2. $0^{\mathrm{TM}} \mathrm{BR}$ will support innovative research to investigate the association of EC and health outcomes, as well as new strategies based on emerging behavioral theories to enhance nutritional education policy.
\end{abstract}

Keywords: eating competence; validation; questionnaire; psychometrics

\section{Introduction}

Eating is a complex process composed of learned behavior, social expectations, acquired tastes, attitudes, and feelings about eating and/or about a food item [1]. Eating competence (EC) is described as an attitudinal and behavioral concept that has been associated with higher diet quality and better nutrition [2-4]. EC has been increasingly studied in some countries since competent eaters tend to have higher dietary quality [2,3], more excellent parent modeling of healthful eating behaviors [5,6], and are physically more active [7]. Additionally, they tend to have more positive attitudes and behaviors toward food and eating [8,9] and less stress [10], as well as lower blood pressure [11], greater weight 
satisfaction [9], and less overweight/obesity [12,13]. Furthermore, EC is associated with better sleep quality [14-16], less disordered eating [12,13,17], and less emotional and uncontrolled eating [12,13]. Recent findings suggest that improving eating competence, especially for planning and having regular meals, could promote adherence to a healthy diet and, in the long term, also support the prevention of type 2 diabetes [18].

In this sense, the Satter Eating Competence Model (ecSatter) was proposed as a biopsychosocial model of eating behavior considering four components: Eating Attitudes-having relaxed enjoyment of preferred foods in satisfying amounts; Food Acceptance-being interested in food, experimenting with unfamiliar food, and achieving dietary variety based on food enjoyment and learned food preferences; Internal Regulation-being naturally attentive to internal signals of hunger, appetite, and satiety to guide how much to eat, supporting stable body weight; and Contextual Skills-having resources to manage the food context, planning and providing regular and reliable opportunities to eat $[1,4]$. $\mathrm{EC}$ is the result of the successful adoption of these four components [13]. It is a behavioral model not focused on nutrients, portion size, or food groups. Instead, it focuses on enjoying food and eating, paying attention to variety in the diet, attending to signals of hunger and satiety, and preparing meals and snacks regularly with some attention to nourishing food and the environment in which it is consumed $[1,19]$. The increasing prevalence and severity of diseases related to food and nutrition point to the need for behavioral approaches to understand food choices [20]. In this context, measuring the components of EC is relevant in order to promote nutritional health.

Therefore, the Satter Eating Competence Inventory (ecSI2. $\left.0^{\mathrm{TM}}\right)$ instrument evaluates EC using the interrelated spectrum of eating attitudes and behaviors. The instrument is composed of a 16-question tool designed to assess the four components of EC. This tool allows researchers and educators to follow intervention outcomes and to explore the eating competence construct [21]. It is validated for English use and has been translated and approved in Arabic, German, Japanese, Finnish, and Spanish [21].

However, there is no study using this tool in developing countries, and the ecSI2. $0^{\mathrm{TM}}$ has not been validated for Latin American countries, like Brazil. Poor diet quality, overweight, and other chronic diseases have been increasing among Brazilian adults [22], and little has been achieved to improve healthy eating habits in most of the Brazilian population despite the knowledge about the relationship between food and health. New findings of eating behavior could be useful to trace health promotion policies targeted to the Brazilian population.

Therefore, the present study aimed to translate and validate the ecSI2. $0^{\mathrm{TM}}$ from English to Brazilian Portuguese. We expect that this new tool will allow future research on EC among the Brazilian population. Potentially, this could also help health professionals and governmental institutions to develop strategies and public policies concerning diet, nutrition, and health.

\section{Materials and Methods}

This cross-sectional study, approved by the Ethics Committee of Santa Marta's Institute of Teaching and Research, Federal District, Brazil (CAAE 24415819.2.0000.8101), was performed in three steps: (i) translation and back-translation of the original ecSI2.0 $0^{\mathrm{TM}}$ to Brazilian Portuguese; (ii) evaluation of reproducibility; (iii) a pilot study to validate the questionnaire for the Brazilian adult population (internal consistency and factor validity).

\subsection{Translation and Back-Translation of the ecSI2.0 $0^{\mathrm{TM}}$}

Translating an existing research instrument into another language is more convenient than developing a new instrument and allows comparisons among people from different countries [23]. The quality of the translation affects the validity of the results, and the adaptation process has to consider linguistic and cultural differences [24].

The original ecSI2.0 $0^{\mathrm{TM}}$ inventory consists of 16 items scored on a five-point Likert scale and assigns values as following: Always $=3$; Often $=2$; Sometimes $=1$, Rarely $=0$; Never $=0$. The score is defined as the sum of the responses for each of these items. Thus, ecSI2. $0^{\mathrm{TM}}$ can take values from 
0 to 48 [21]. Competent eaters have a minimum total score of 32 [12,21], and higher values in the ecSI2. $0^{\mathrm{TM}}$ indicate greater EC. This index has four domains: Eating Attitude, composed of six items ("I am relaxed about eating"; "I am comfortable about eating enough"; "I feel it is okay to eat food that I like"; "I am comfortable with my enjoyment of food and eating"; "I trust myself to eat enough for me"; and "I enjoy food and eating); Food Acceptance, with three items ("I experiment with new food and learn to like it"; "If the situation demands, I can "make do" by eating food I don't much care for"; and "I eat a wide variety of foods"); Internal Regulation, consisting of two items ("I eat as much as I am hungry for" and "I eat until I feel satisfied"); and Contextual Skills, with five items ("I have regular meals"; "I tune in to food and pay attention to eating"; "I make time to eat"; "I consider what is good for me when I eat"; and "I plan for feeding myself") [19,21]. There are no established score cutoffs for each of the subscales [21].

In this step, the ecSI2.0 $0^{\mathrm{TM}}$ inventory was translated to Brazilian Portuguese according to the translation process indicated by the NEEDs Center [25]. Two native Brazilian Portuguese speakers, who had not previously been exposed to the ecSI2. $0^{\mathrm{TM}}$, translated the instrument from English into Brazilian Portuguese. A researcher, familiar with the Satter Eating Competence Model, discussed with the two translators the two versions and reached a single version. Five native speakers, who were naïve to the subject, pretested the preliminary Brazilian Portuguese version. Each of the test-takers was asked to express, question by question, their understanding of the meaning of each item. Based on the test-taker responses, the translators came up with a single preliminary Brazilian Portuguese version. A native Brazilian Portuguese speaker, who was not involved in the previous steps, performed the back-translation from the Brazilian Portuguese version into English. Researchers sent the translation table (with translation, back-translation, and comments) to the NEEDs Center [21] for the agreement assessment of the intent and meaning of the items. NEEDs Center researchers suggested some changes that were discussed and evaluated by the Brazilian researchers and the translators, to reach the final ecSI2.0 $0^{\mathrm{TM}} \mathrm{BR}$ by group consensus. The use of translation, in conjunction with back-translation, including bilingual and monolingual participants, is the recommended method to maintain the idea of each item in another language [23].

\subsection{Evaluation of Reproducibility of the ecSI2. $0^{T M} B R$}

The reproducibility of the ecSI2.0 $0^{\mathrm{TM}} \mathrm{BR}$ was analyzed before a more extensive application. It was assessed for test-retest reliability, as this shows the ability to produce consistent results when used multiple times under nearly similar conditions [26,27]. According to Zou (2012) [28], the sample required for a hypothesized (based on previous data or experience) intraclass correlation coefficient (ICC) of 0.85 to be statistically greater than 0.6 , considering a significance level of $5 \%$ and power of $80 \%$, is 21 observations. For this purpose, on 30 November 2019, considering that not all of the individuals invited would answer the questionnaire, a convenience sample of 50 Brazilian individuals received an invitation through email, messaging apps, and social networks to answer the questionnaire to achieve a minimum of 21 individuals participating in the test-retest. The inclusion criteria were to be Brazilian, over 18 years old, and answer the entire questionnaire. From this sample, 36 met the criteria and answered the questionnaire entirely. To evaluate the reproducibility (test-retest reliability) of the ecSI2.0 ${ }^{\mathrm{TM}} \mathrm{BR}$, the questionnaire was sent again after $24 \mathrm{~h}$, and each of the 36 respondents was asked to answer it. The participants did not previously know about the need for a second response. From the 36 invited participants, 32 accepted to participate again, and the reproducibility was performed using the responses of these 32 Brazilian adults (56.2\% were female, mean age was $41.21 \pm 10.74$ years old, and $96.9 \%$ had a minimum undergraduate schooling level). The mean interval between the two responses was $58.6 \pm 43.2 \mathrm{~h}$, as not all participants responded as soon as they were asked.

The questionnaire was answered using the SurveyMonkey ${ }^{\circledR}$ tool, an online survey platform. The reproducibility of the ecSI2. $0^{\mathrm{TM}} \mathrm{BR}$ was verified by its total score and by domains through the intraclass correlation coefficient (ICC) with two random effect models and absolute agreement definition. 
The analysis was based on a single measure, and values equal to or greater than 0.6 indicated that the instrument had a good level of reproducibility [26].

\subsection{A Pilot Study to Validate the ecSI2.0 $0^{T M} B R$ (Evaluation of Internal Consistency)}

The final ecSI2.0 ${ }^{\mathrm{TM}} \mathrm{BR}$ was validated by a pilot study with a convenience sample of the adult population (20-59 years old) living in the Federal District, Brazil. According to Hair et al. [29], the process of validating a questionnaire requires 20 respondents per item (20:1). In this sense, the minimum sample size was estimated to be 320 participants to validate a questionnaire composed of 16 items. The invitation to participate was sent through email, messaging apps, and social networks. Participants received a consent form approved by the Research Ethics Committee, and those who accepted, met the inclusion criteria (age $\geq 18$ years), and answered the entire questionnaire were included in the pilot study. The SurveyMonkey ${ }^{\circledR}$ tool was used for this step. With the data of this pilot study, the internal consistency of the instrument and its domains were verified using the Cronbach's alpha measure. Values equal to or greater than 0.7 were considered consistent [30].

In addition to the ecSI2.0 $0^{\mathrm{TM}} \mathrm{BR}$, socio-demographic data (gender, age, income, schooling level, and housing area) were collected using the questions from the Brazilian National Institute of Geography and Statistics (IBGE) [31] as a reference to characterize the studied population.

\subsection{Statistical Analysis}

The questionnaire's responsiveness was verified by the floor and ceiling effects. The floor effect is observed when the ecSI2.0 $0^{\mathrm{TM}} \mathrm{BR}$ (and its domains) produces a score equal to zero. The ceiling effect occurs when the instrument (and its domains) reaches maximum values. The factor validity was verified by confirmatory factor analysis. The chi-squared test of minimum discrepancy $\left(\chi^{2}\right)$, the root mean square error of approximation (RMSEA), and the comparative fit index (CFI) evaluated the factor validity [24]. Both RMSEA and CFI range from 0 to 1 (RMSEA $=0$ and CFI $=1$ indicate a perfect fit). The model fit is accepted when RMSEA is less than or equal to 0.05 [32], and CFI is greater than or equal to 0.9 . The scores of the eating competence index were described in terms of means and standard deviation (SD). All tests were performed considering bilateral hypotheses and a $5 \%$ significance level. The analyses were performed using IBM SPSS (IBM SPSS Statistics for Windows, IBM Corp, Armonk, NY, USA) and IBM SPSS Analysis of Moment Structures (AMOS) version 22 (Amos, IBM SPSS, Chicago, IL, USA).

\section{Results}

After four judgment rounds, the ecSI $2.0^{\mathrm{TM}} \mathrm{BR}$ was successfully approved by the NEEDs Center on 10/22/2019 with its 16 items. Figure 1 describes the steps of the translation and validation of the ecSI2.0 ${ }^{\mathrm{TM}} \mathrm{BR}$.

The reproducibility (test-retest reliability) was verified using the intraclass correlation coefficient (ICC). All domains of the ecSI2.0 ${ }^{\mathrm{TM}} \mathrm{BR}$ and the total score are shown in Table 1 . Analyses revealed that ICC $=0.931$ for the ecSI2.0 ${ }^{\mathrm{TM}} \mathrm{BR}$ total scale, 0.927 for Eating Attitudes, 0.809 for Food Acceptance, 0.876 for Internal Regulation, and 0.946 for Contextual Skills.

Table 1. Reproducibility of the ecSI $2 \cdot 0^{\mathrm{TM}} \mathrm{BR}$ domains ( $n=32$ participants).

\begin{tabular}{ccc}
\hline ecSI2.0 Domains & ICC $^{\text {a }}(p)$ & $\mathbf{9 5 \% ~ C I ~}$ \\
\hline Eating Attitudes & $0.927(<0.001)$ & $0.850-0.965$ \\
Food Acceptance & $0.809(<0.001)$ & $0.658-0.872$ \\
Internal Regulation & $0.876(<0.001)$ & $0.749-0.939$ \\
Contextual Skills & $0.946(<0.001)$ & $0.889-0.974$ \\
Total & $0.931(<0.001)$ & $0.857-0.967$ \\
\hline
\end{tabular}

${ }^{\mathrm{a}}$ Interclass correlation coefficient (ICC). 


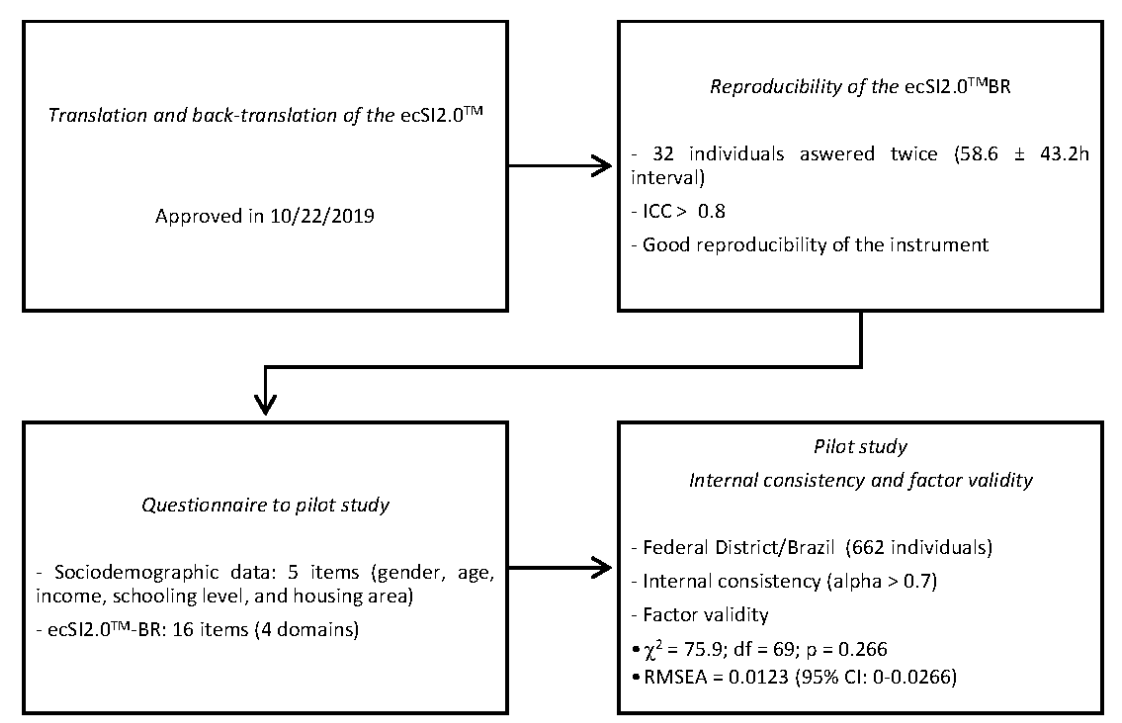

Figure 1. Flowchart of the steps to translate and validate the Satter Eating Competence Inventory in Brazilian-Portuguese (ecSI2.0 $\left.{ }^{\mathrm{TM}} \mathrm{BR}\right)$.

\section{A Pilot Study to Validate the ecSI2.0 ${ }^{T M}$ BR for the Brazilian Adult Population}

The questionnaire with socio-demographic data and the ecSI2.0 ${ }^{\mathrm{TM}} \mathrm{BR}$ were available online from December 2019 to February 2020 using the SurveyMonkey ${ }^{\circledR}$ platform. On the platform, only one answer per device was allowed to avoid duplicates and to make sure that respondents were unique completers. From the 678 individuals who responded to the online questionnaire, the final sample was composed of 662 participants, since some participants $(n=16)$ did not provide all the data necessary for their inclusion in the survey. Table 2 shows the socio-demographic characteristics of the individuals who participated in the pilot study. Most of the participants were female $(n=496,74.9 \%)$, had a good distribution across the age groups (mean age $40.33 \pm 12.55$ ), and presented a higher level of schooling and income.

Table 2. Socio-demographic characteristics of the individuals ( $n=662$, Federal District, Brazil).

\begin{tabular}{cccc}
\hline \multirow{2}{*}{ Gender } & & \multicolumn{2}{c}{ Sample $(n=662)$} \\
\cline { 3 - 4 } & & Freq & $\%$ \\
\hline \multirow{2}{*}{ Age } & Female & 496 & $74.9 \%$ \\
& Male & 166 & $25.1 \%$ \\
\hline \multirow{2}{*}{ Schooling Level } & Up to 30 years & 169 & $25.5 \%$ \\
& 31 to 40 years & 146 & $22.1 \%$ \\
& 41 to 50 years & 184 & $27.8 \%$ \\
& 51 to 59 years & 163 & $24.6 \%$ \\
\hline \multirow{2}{*}{ Income * } & High School & 55 & $8.3 \%$ \\
& Undergraduate & 256 & $38.7 \%$ \\
& Graduate & 351 & $53.0 \%$ \\
\hline & Up to 3000 BRL & 82 & $12.4 \%$ \\
& 3001 to 5000 BRL & 62 & $9.4 \%$ \\
& 5001 to 10,000 BRL & 130 & $19.6 \%$ \\
& 10,001 to 20,000 BRL & 201 & $30.4 \%$ \\
& More than 20,000 BRL & 187 & $28.2 \%$ \\
\hline
\end{tabular}

* BRL: Brazilian Real is the official currency of Brazil and 1.00 USD = 5.56 BRL (5 May 2020).

Table 3 shows data from the internal consistency evaluation. Analyses revealed that Cronbach's alpha coefficient $=0.869$ for the ecSI $2.0^{\mathrm{TM}}$ BR total scale, 0.793 for Eating Attitudes, 0.728 for Food Acceptance, 0.527 for Internal Regulation, and 0.822 for Contextual Skills. 
Table 3. The ecSI2.0 ${ }^{\mathrm{TM}} \mathrm{BR}$ scores, responsiveness, and internal consistency of the questionnaire.

\begin{tabular}{ccccccc}
\hline & Mean (SD) & Median (IQR *) & Range & Floor Effect (\%) & Ceiling Effect (\%) & Cronbach's Alpha \\
\hline Eating Attitudes & $11.90(3.87)$ & $12(9-15)$ & $0-18$ & $0.3 \%$ & $6.0 \%$ & 0.793 \\
Food Acceptance & $5.11(2.44)$ & $5(3-7)$ & $0-9$ & $3.9 \%$ & $9.1 \%$ & 0.728 \\
Internal Regulation & $3.76(1.53)$ & $4(3-5)$ & $0-6$ & $3.2 \%$ & $15.1 \%$ & 0.527 \\
Contextual Skills & $9.26(3.70)$ & $10(7-12)$ & $0-15$ & $1.2 \%$ & $6.5 \%$ & 0.822 \\
Total & $30.03(8.85)$ & $31(24.37)$ & $0-48$ & $0.2 \%$ & $0.6 \%$ & 0.869 \\
\hline
\end{tabular}

${ }^{*}$ IQR: Interquartile range.

In addition, the factor validity was examined by confirmatory factor analysis. Table 4 presents the standardized regression weights (factor loadings) between each domain and individual items of the ecSI2.0 ${ }^{\mathrm{TM}} \mathrm{BR}$.

Table 4. Standardized regression weights between domains and individual items of the ecSI2.0 ${ }^{\mathrm{TM}} \mathrm{BR}$.

\begin{tabular}{ccc}
\hline Domain & Item & Factor Loadings \\
\hline Eating Attitudes & I am relaxed about eating & 0.7246 \\
& I am comfortable about eating enough & 0.7149 \\
& I enjoy food and eating & 0.6569 \\
& I am comfortable with my enjoyment of food and eating & 0.6763 \\
& I trust myself to eat enough for me & 0.6463 \\
Food Acceptance & I feel it is okay to eat food that I like & 0.7562 \\
\hline Internal Regulation & I experiment with new food and learn to like it & 0.6926 \\
& If situations demand I can "make do" by eating food I & 0.7280 \\
\hline Contextual Skills & don't much care for & 0.7730 \\
& I eat a wide variety of food & 0.6134 \\
& I eat as much as I am hungry for & 0.6062 \\
\hline & I eat until I feel satisfied & 0.8987 \\
& I tune to food and pay attention to eating & 0.7725 \\
& I make time to eat & 0.7451 \\
& I have regular meals & 0.8947 \\
& I consider what is good for me when I eat & 0.7198 \\
\hline
\end{tabular}

\section{Discussion}

This study translated and validated the Satter Eating Competence Inventory (ecSI2. $0^{\mathrm{TM}}$ ) from English to Brazilian Portuguese. In a Latin American country, the present study is the first to perform the validation of an instrument to measure EC using Brazilian Portuguese. The process included the translation and back-translation of the original ecSI2. $0^{\mathrm{TM}}$ to Brazilian Portuguese, the evaluation of its reproducibility, and a pilot study to validate the Brazilian version using internal consistency and factor validity. The results indicated an acceptable model fit, and all four components of the ecSI2.0 were correlated with each other and had a high internal consistency. Although the ecSI2.0 $0^{\mathrm{TM}}$ translation has been approved for other languages, it is only validated for English and Finnish use [21]. To enable the use of this instrument in Brazilian Portuguese, the linguistic validation process is recommended because the original instrument was developed in a language other than the target population language $[24,33]$. Therefore, the first step of this study was to translate/retranslate the ecSI2. $0^{\mathrm{TM}}$. Back-translation is commonly used to check the accuracy of translation in cross-cultural studies [23]. Tilles-Tirkkonen et al. [34] explored the utility of a preliminary Finnish translation of the ecSI2.0 $0^{\mathrm{TM}}$ for evaluating EC in adolescents. They pointed out that an approved back-translation was needed to confirm the validity of their findings [34]. The present translation of the ecSI2.0 $0^{\mathrm{TM}}$ followed the instructions of the NEEDs Center [25]. Thus, the ecSI2.0 ${ }^{\mathrm{TM}} \mathrm{BR}$ was approved by the NEEDs Center [25], and it is in agreement with the original ecSI2.0 ${ }^{\mathrm{TM}}$. 
The reproducibility analysis was performed using test-retest reliability to assure the capacity to reproduce the results. The sample was higher than the minimum required $(n \geq 21)$. Participants were 32 Brazilian adults ( $56.2 \%$ female), with a mean age of $41.21 \pm 10.74$ and a good level of schooling and income, who answered the questionnaire at two different times. The mean interval between the two responses was $58.6 \pm 43.2 \mathrm{~h}$ because respondents took from $24 \mathrm{~h}$ to 15 days to answer the second request. The interval from a minimum of $24 \mathrm{~h}$ to a maximum of 15 days was selected to minimize the effect of possible confounding variables, such as increasing or decreasing eating competence, which could affect the data. This time interval can be considered sufficient for the reproducibility analysis because it is not expected that eating competence would change over this period. According to McIntire and Miller [27], for test-retest reliability, the interval between the two responses may vary from a few hours to up to several years depending on the construct being measured, on the stability of the construct over time, and on the target population. Additionally, as the interval lengthens, test-retest reliability declines because the number of opportunities for the participants or situation to change increases over time. All domains of the ecSI2.0 ${ }^{\mathrm{TM}} \mathrm{BR}$ and the total score showed an ICC $>0.8$ (Table 2). None of the items composing the final instrument showed significant divergence among the 32 evaluators $(p<0.001)$, indicating excellent reproducibility [35].

After this stage, a pilot study was performed with 662 adults living in the Federal District, Brazil (74.9\% female), with a mean age of $40.33 \pm 12.55$. This sample size population was twice as large as the minimum sample required to validate a tool composed of 16 items. The good internal consistency of the ecSI2.0BR ${ }^{\mathrm{TM}}$ was confirmed, as the Cronbach's alpha coefficient for the total score was 0.869 (Table 3). In general, the ecSI2.0 TMBR presented good acceptability [36], showing total floor and ceiling effects of $\leq 0.6 \%$ (Table 3). In the confirmatory factor analysis, the four domains presented a good fit, and all items showed factor loadings $>0.6$ and were not considered for removal [29].

Except for the internal regulation domain, which presented an alpha of 0.527 , the other items of the questionnaire showed an alpha of $>0.7$, indicating good reliable internal consistency (Table 3). These results are in line with Stotts and Lohse (2007) [37], who also found a Cronbach's alpha coefficient score of $<0.7$ for internal regulation when performing a study to assess the test-retest reliability of the ecSI ${ }^{\mathrm{TM}}$ to determine its usefulness as a measure of EC. At that time, the Internal Regulation construct was composed of three statements, and the authors suggested further development and evaluation of the internal regulation subscale [37]. Considering that the Cronbach's alpha value is affected by the number of items, the low value found in the present study may be explained by the small scale [30]. In 2019, Godleski et al. performed a confirmatory factor analysis to explore the construct validity of the ecSI2.0 ${ }^{\mathrm{TM}}$ using data from three heterogeneous socioeconomic samples. After that, the ecSI2.0 $0^{\mathrm{TM}}$ was restructured, and the item "I trust myself to eat enough for me" moved from Internal Regulation to the Eating Attitudes subscale. The internal regulation domain is now composed of only two statements [19], which may also have affected the low Cronbach's alpha value found for the internal Regulation domain [30]. This recent reformulation supports the EC construct by categorizing the 16 items into four subscales: Eating Attitudes (six items), Food Acceptance (three items), Internal Regulation (two items), and Contextual Skills (five items). The authors encourage exploring the performance of the ecSI2.0 ${ }^{\mathrm{TM}}$ in linguistically diverse populations with confirmatory factor analysis [19], as it was done in the present study using Brazilian Portuguese. The four domains of the ecSI2.0-BR ${ }^{\mathrm{TM}}$ showed a good fit in the confirmatory factor analysis, which means that the measures of the constructs are consistent with the understanding of their nature.

A limitation of this study might be the online application of a self-administered instrument. This method was chosen because it is less costly and less invasive. It requires less effort, and less time for the researchers and the participants, than a face-to-face interview, which can also cause difficulties in reaching part of a population, due to geographical limitations [38]. A study comparing online and paper-pencil formats found that the ecSI ${ }^{\mathrm{TM}}$ scores did not differ according to the method of survey completion [12]. Data from the Brazilian population (2017) show that three out of four Brazilians have internet access, and the level of cellphone possession, a primary tool used to access the internet, 
increased from $92.6 \%$ to $93.2 \%$ [39]. Therefore, the online self-reported method shows efficiency for data collection, the possibility to reach a more significant number of participants, and a positive impact on cost.

Another limitation of the present study might be the fact that our sample had a higher proportion of female (74.9\%) respondents. However, in Brazil, females play a central role in family food purchasing and preparation, reporting sole responsibility for household food decisions [31,40]. Moreover, the first study designed to validate the ecSI ${ }^{\mathrm{TM}}$ [12] also presented a predominantly female sample $(78.7 \%)$. In general, women tend to be more concerned about their health and participate in health surveys more than men $[33,41]$. Thus, this high proportion of females could have resulted in a higher validity. Nevertheless, the sample was larger than the minimum required for the validation process, thereby making the study findings remarkable.

There was also a selection bias regarding the educational and socioeconomic level of the sample, as they were mostly graduated and presented high income. The ability to eat competently may be affected by food insecurity and/or income restrictions. For example, Lohse et al. (2007) reported that "worrying about money for food" and "running out of food by the end of the month" were associated with a lack of eating competence [12]. Krall and Lohse [13], after noticing that lower income persons tend to show lower EC, performed a study with 507 low-income women, aged 18 to 45 years, to investigate their interpretation of the meaning of the ecSI ${ }^{\mathrm{TM}}$ and its validation with a lower income audience. Although the ecSITM for low-income people was shown to be valid in measuring EC for persons with a higher socioeconomic position [42], this relationship needs to be tested among the socioeconomically disadvantaged Brazilian population as well. According to a census by the Brazilian Institute of Geography and Statistics (IBGE), approximately half of the Brazilian population is 25 years of age or younger and has less than an eighth-grade education [31]. The mean age of the pilot study sample was $40.33 \pm 12.55$, and $53 \%$ of the respondents had a graduate degree. In the pilot study, participants were more educated than the Brazilian population in general, and the mean age was rather high, which has been associated with higher eating competence [2,12], so the results cannot be generalized to young people and persons of a lower socioeconomic position. Therefore, further studies are necessary to evaluate EC in these populations.

\section{Conclusions}

The Brazilian Portuguese version of the ecSI2. $0^{\mathrm{TM}}$ was the first tool designed to measure EC in the Brazilian population. Validation is a continuing and ongoing process [26], and in this study, the ecSI2.0 $0^{\mathrm{TM}} \mathrm{BR}$ showed good reproducibility, internal consistency, and a good fit in the confirmatory factor analysis. It represents the first tool designed in Brazilian Portuguese to investigate EC among Brazilian adults. We expect the ecSI2.0 ${ }^{\mathrm{TM}} \mathrm{BR}$ will support innovative research to investigate the association of EC and health outcomes, as well as new strategies based on emerging behavioral theories to enhance nutritional education policy.

Author Contributions: Conceptualization, F.L.N.d.Q., R.P.Z., V.C.G., and R.B.A.B.; methodology, F.L.N.d.Q., R.P.Z., and E.Y.N.; validation, R.P.Z. and E.Y.N.; formal analysis, F.L.N.d.Q., R.P.Z., and E.Y.N.; investigation, F.L.N.d.Q.; resources, F.L.N.d.Q., R.P.Z., and W.M.C.A.; data curation, F.L.N.d.Q.; writing-original draft preparation, F.L.N.d.Q., R.P.Z., and R.B.A.B.; writing-review and editing, F.L.N.d.Q., R.P.Z., V.C.G., E.Y.N., and R.B.A.B.; visualization, F.L.N.d.Q., R.P.Z., V.G., E.Y.N., and R.B.A.B.; supervision, R.P.Z.; project administration, F.L.N.d.Q. and R.P.Z.; funding acquisition, F.L.N.Q. and W.M.C.A. All authors have read and agreed to the published version of the manuscript.

Funding: This research was funded by DPI/UnB.

Acknowledgments: Capes: CNPQ, PPGNH/UnB, NEEDs Center, Barbara Lohse, and Ellyn Satter for their participation in the translation process and valuable comments on the manuscript.

Conflicts of Interest: The authors declare no conflict of interest. 


\section{References}

1. Satter, E. Eating Competence: Definition and Evidence for the Satter Eating Competence Model. J. Nutr. Educ. Behav. 2007, 39, 142-153. [CrossRef]

2. Lohse, B.; Bailey, R.L.; Krall, J.S.; Wall, D.E.; Mitchell, D.C. Diet quality is related to eating competence in cross-sectional sample of low-income females surveyed in Pennsylvania. Appetite 2012, 58, 645-650. [CrossRef] [PubMed]

3. Lohse, B.; Psota, T.; Zazpe, I.; Sorli, V.; Salas-salvado, J.; Ros, E. Eating Competence of Elderly Spanish Adults Is Associated with a Healthy Diet and a Favorable Cardiovascular Disease Risk Profile 1-3. J. Nutr. 2010, 140, 1322-1327. [CrossRef] [PubMed]

4. Satter, E. Eating Competence: Nutrition Education with the Satter Eating Competence Model. J. Nutr. Educ. Behav. 2007, 39, S189-S194. [CrossRef] [PubMed]

5. Lohse, B.; Cunningham-Sabo, L. Eating Competence of Hispanic Parents Is Associated with Attitudes and Behaviors That May Mediate Fruit and Vegetable-Related Behaviors of 4th Grade Youth. J. Nutr. 2012, 142, 1903-1909. [CrossRef]

6. Tylka, T.L.; Eneli, I.U.; Kroon Van Diest, A.M.; Lumeng, J.C. Which adaptive maternal eating behaviors predict child feeding practices? An examination with mothers of 2-5-years-old children. Eat Behav. 2013, 14, 57-63. [CrossRef]

7. Lohse, B.; Arnold, K.; Wamboldt, P. Evaluation of About Being Active, an online lesson about physical activity shows that perception of being physically active is higher in eating competent low-income women. BMC Womens Health 2013, 13, 94. [CrossRef]

8. Stotts Krall, J.; Lohse, B. Interviews with Low-Income Pennsylvanians Verify a Need to Enhance Eating Competence. J. Am. Diet. Assoc. 2009, 109, 468-473. [CrossRef]

9. Clifford, D.; Keeler, L.A.; Gray, K.; Steingrube, A.; Morris, M.N. Weight Attitudes Predict Eating Competence among College Students. Fam. Consum. Sci. Res. J. 2010, 39, 184-193. [CrossRef]

10. Järvelä-Reijonen, E.; Karhunen, L.; Sairanen, E.; Rantala, S.; Laitinen, J.; Puttonen, S.; Peuhkuri, K.; Hallikainen, M.; Juvonen, K.; Myllymäki, T.; et al. High perceived stress is associated with unfavorable eating behavior in overweight and obese Finns of working age. Appetite 2016, 103, 249-258. [CrossRef]

11. Psota, T.L.; Lohse, B.; West, S.G. Associations between Eating Competence and Cardiovascular Disease Biomarkers. J. Nutr. Educ. Behav. 2007, 39, S171-S178. [CrossRef] [PubMed]

12. Lohse, B.; Satter, E.; Horacek, T.; Gebreselassie, T.; Oakland, M.J. Measuring Eating Competence: Psychometric Properties and Validity of the ecSatter Inventory. J. Nutr. Educ. Behav. 2007, 39, S154-S166. [CrossRef] [PubMed]

13. Krall, J.S.; Lohse, B. Validation of a measure of the Satter eating competence model with low-income females. Int. J. Behav. Nutr. Phys. Act. 2011, 8, 1-10. [CrossRef] [PubMed]

14. Quick, V.; Byrd-Bredbenner, C.; White, A.A.; Brown, O.; Colby, S.; Shoff, S.; Lohse, B.; Horacek, T.; Kidd, T.; Greene, G. Eat, sleep, work, play: Associations of weight status and health- related behaviors among young adult college students. Am. J. Health Promot. 2014, 29, e54-e72. [CrossRef] [PubMed]

15. Quick, V.; Shoff, S.; Lohse, B.; White, A.; Horacek, T.; Greene, G. Relationships of eating competence, sleep behaviors and quality, and overweight status among college students. Eat Behav. 2015, 19, 15-19. [CrossRef]

16. Quick, V.; Byrd-Bredbenner, C.; Shoff, S.; White, A.A.; Lohse, B.; Horacek, T.; Colby, S.; Brown, O.; Kidd, T.; Greene, G. Relationships of Sleep Duration With Weight-Related Behaviors of U.S. College Students. Behav. Sleep Med. 2016, 14, 565-580. [CrossRef]

17. Brown, L.B.; Larsen, K.J.; Nyland, N.K.; Eggett, D.L. Eating competence of college students in an introductory nutrition course. J. Nutr. Educ. Behav. 2013, 45, 269-273. [CrossRef]

18. Tilles-Tirkkonen, T.; Aittola, K.; Männikkö, R.; Absetz, P.; Kolehmainen, M.; Schwab, U.; Lindström, J.; Lakka, T.; Pihlajamäki, J.; Karhunen, L. Eating competence is associated with lower prevalence of obesity and better insulin sensitivity in finnish adults with increased risk for type 2 diabetes: The stopdia study. Nutrients 2020, 12, 104. [CrossRef]

19. Godleski, S.; Lohse, B.; Krall, J.S. Satter Eating Competence Inventory Subscale Restructure After Confirmatory Factor Analysis. J. Nutr. Educ. Behav. 2019, 51, 1003-1010. [CrossRef] 
20. Burton, E.T.; Smith, W.A. Mindful Eating and Active Living: Development and Implementation of a Multidisciplinary Pediatric Weight Management Intervention. Nutrients 2020, 12, 1425. [CrossRef]

21. NEEDs Center Protocol for the Use of the ecSatter Inventory 2.0. Available online: https://www.needscenter. org/wp-content/uploads/2019/09/ecSI-2.0-Usage-Protocol-2-1.pdf (accessed on 9 March 2020).

22. BRASIL, M. VIGITEL 2019, Vigilância de Fatores de Risco e Proteção Para Doenças Crônicas Por Inquerito Telefônico, 1st ed.; Da S. Brasil, M., Ed.; Secretaria de Vigilância em Saúde. Departamento de Análise em Saúde e Vigilância de Doenças não Transmissíveis: Brasília, Brazil, 2020; ISBN 9788533419568.

23. Ali, M.M. Are we asking the same questions in different contexts: Translation techniques in cross-culture studies in science education? J. Turk. Sci. Educ. 2016, 13, 31-44. [CrossRef]

24. Conti, M.A.; Scagliusi, F.; Queiroz, G.K.O.; Hearst, N.; Cordás, T.A. Cross-cultural adaptation: Translation and Portuguese language content validation of the tripartite influence scale for body dissatisfaction | Adaptação transcultural: Tradução e validação de conteúdo para o idioma Português do modelo da Tripartite Influe. Cad. Saude Publ. 2010, 26, 503-513. [CrossRef] [PubMed]

25. NEEDs Center ecSI-2.0-Translation-Guide-2. Available online: https://www.needscenter.org/wp-content/ uploads/2018/12/ecSI-2.0-Translation-Guide-2.pdf (accessed on 21 February 2020).

26. Mchugh, M.L. Lessons in biostatistics Interrater reliability:The kappa statistic. Biochem. Med. 2012, 22, 276-282. [CrossRef]

27. McIntire, S.A.; Miller, L.A. Test-Retest Reliability. In Foundations of Psychological Testing: A Practical Approach; Sage Publications: New York, NY, USA, 2007; p. 182.

28. Zou, G.Y. Sample size formulas for estimating intraclass correlation coefficients with precision and assurance. Stat. Med. 2012, 31, 3972-3981. [CrossRef]

29. Hair, J.F.; Anderson, R.E.; Tatham, R.L.; Black, W.C. Multivariate Data Analysis, 7th ed.; Bookman: Englewood Cliffs, NJ, USA, 2009; ISBN 978-0-02-349020-0.

30. Streiner, D.L.; Streiner, D.L. Starting at the Beginning: An Introduction to Coefficient Alpha and Internal Consistency. J. Pers. Assess. 2003, 80, 99-103. [CrossRef]

31. IBGE IBGE-Instituto Brasileiro de Geografia: Pesquisa Nacional por Amostra de Domicílio Contínua (PNAD Contínua). Available online: http://www.ibge.gov.br/estatisticas-novoportal/sociais/educacao/1727pnad-continua.html (accessed on 22 April 2020).

32. Hu, L.; Bentler, P. Cutoff criteria for fit indexes in covariance structure analysis: Conventional criteria versus new alternatives. Struct. Equ. Model 1999, 6, 1-55. [CrossRef]

33. Pratesi, C.P.; Häuser, W.; Uenishi, R.H.; Selleski, N.; Nakano, E.Y.; Gandolfi, L.; Pratesi, R.; Zandonadi, R.P. Quality of life of celiac patients in Brazil: Questionnaire translation, cultural adaptation and validation. Nutrients 2018, 10, 1167. [CrossRef]

34. Tilles-Tirkkonen, T.; Outi, N.; Sakari, S.; Jarmo, L.; Kaisa, P.; Leila, K. Preliminary Finnish measures of Eating Competence suggest association with health-promoting eating patterns and related Psychobehavioral factors in 10-17 years old adolescents. Nutrients 2015, 7, 3828-3846. [CrossRef]

35. Cicchetti, D.V. Guidelines, Criteria, and Rules of Thumb for Evaluating Normed and Standardized Assessment Instruments in Psychology. Psychol. Assess. 1994, 6, 284-290. [CrossRef]

36. Kline, R. Principles and Practice of Structural Equation Modeling, 3rd ed.; Guilford publications: New York, NY, USA, 2010; ISBN 9781462523344.

37. Stotts, J.L.; Lohse, B. Reliability of the ecSatter Inventory as a Tool to Measure Eating Competence. J. Nutr. Educ. Behav. 2007, 39, 167-170. [CrossRef]

38. Evans, J.R.; Mathur, A. The value of online surveys. Int. Res. 2005, 15, 195-219. [CrossRef]

39. IBGE Instituto Brasileiro de Geografia e Estatistica PNAD Contínua TIC 2017: Internet Chega a Três em Cada Quatro Domicílios do País. Available online: http://agenciadenoticias.ibge.gov.br/agencia-sala-de-imprensa/ 2013-agencia,-de-noticias/releases/23445-pnad-continua-tic-2017-internet-chega-a-tres-em-cada-quatrodomicilios-do-pais (accessed on 21 April 2020).

40. Ministério do Planejamento, Orçamento e Gestão Instituto Brasileiro de Geografia e Estatística-IBGE POF-Pesquisa de Orçamentos Familiares. Available online: https://biblioteca.ibge.gov.br/visualizacao/livros/ liv50063.pdf (accessed on 22 April 2020). 
41. Davidson, D.J.; Freudenburg, W.R. Gender and environmental risk concerns:A review and analysis of available research. Environ. Behav. 1996, 28, 302-339. [CrossRef]

42. Lohse, B. The Satter Eating Competence Inventory for Low-income persons is a valid measure of eating competence for persons of higher socioeconomic position. Appetite 2015, 87, 223-228. [CrossRef] [PubMed]

(C) 2020 by the authors. Licensee MDPI, Basel, Switzerland. This article is an open access article distributed under the terms and conditions of the Creative Commons Attribution (CC BY) license (http://creativecommons.org/licenses/by/4.0/). 